Article

\title{
Financial Impacts of Net-Metered Distributed PV on a Prototypical Western Utility's Shareholders and Ratepayers
}

\author{
Peter Cappers ${ }^{1, *}$, Andrew Satchwell ${ }^{1} \mathbb{D}$, Will Gorman ${ }^{1}\left(\mathbb{D}\right.$ and Javier Reneses ${ }^{2} \mathbb{C}$ \\ 1 Lawrence Berkeley National Laboratory, 1 Cyclotron Road, Berkeley, CA 94720, USA; \\ asatchwell@lbl.gov (A.S.); wgorman@lbl.gov (W.G.) \\ 2 Institute for Research in Technology, Technical School of Engineering (ICAI), \\ Universidad Pontificia Comillas, 28015 Madrid, Spain; javier.reneses@iit.comillas.edu \\ * Correspondence: pacappers@lbl.gov; Tel.: +1-315-637-0513
}

Received: 5 November 2019; Accepted: 13 December 2019; Published: 16 December 2019

\begin{abstract}
Distributed solar photovoltaic (DPV) under net-energy metering with volumetric retail electricity pricing has raised concerns among utilities and regulators about adverse financial impacts for shareholders and ratepayers. Using a pro forma financial model, we estimate the financial impacts of different DPV deployment levels on a prototypical Western U.S. investor-owned utility under a varied set of operating conditions that would be expected to affect the value of DPV. Our results show that the financial impacts on shareholders and ratepayers increase as the level of DPV deployment increases, though the magnitude is small even at high DPV penetration levels. Even rather dramatic changes in DPV value result in modest changes to shareholder and ratepayer impacts, but the impacts on the former are greater than the latter (in percentage terms). The range of financial impacts are driven by differences in the amount of incremental capital investment that is deferred, as well as the amount of incremental distribution operating expenses that are incurred. While many of the impacts appear relatively small (on a percentage basis), they demonstrate how the magnitude of impacts depend critically on utility physical, financial, and operating characteristics.
\end{abstract}

Keywords: distributed solar PV; financial analysis; net-energy metering; investor-owned utility; earnings; return on equity; retail rates; ratepayer bills

\section{Introduction}

Residential solar power is rapidly expanding in the United States (U.S.). In 2018, there was a 7\% increase in residential distributed solar photovoltaic (DPV) deployment [1]. Such large increases in the deployment of DPV in the U.S. over the previous 5-7 years has been attributed to significant declines in equipment costs [2], state and federal tax credits, and electric utility net-energy metering (NEM) compensation programs [3]. NEM is a billing mechanism that credits customers with distributed generation systems for any electricity they export to the grid [4]. Use of NEM in conjunction with volumetric retail electricity pricing (i.e., uniform compensation of generation in excess of consumption, regardless of its characteristics such as time of generation), however, has also raised concerns among utilities and regulators of higher retail electric power rates and shifting of costs from DPV to non-DPV customers [5]. While current amounts of DPV in many jurisdictions are small and thus any retail rate and cost-shifting concerns may be anticipatory in nature, NEM reforms have been proposed and, in certain cases, adopted by state public utility commissions [6]. Importantly, most reforms change the DPV system payback periods and have the potential to reduce distributed solar PV deployment [7]. Barbose et al. [8], for example, modeled effects of a reduction in NEM compensation for grid exports 
from retail to wholesale electric power rates. They found that this reduction in NEM compensation would reduce residential 2050 solar PV deployment by approximately $20 \%$.

Electric investor-owned utilities (IOUs), particularly those in the United States, are concerned about the effects of DPV on future earnings opportunities from deferred or avoided capital investments under existing regulatory and business models [9]. IOUs increase their earnings base by investing in capital, which may be growth-related (e.g., new distribution system investments and generating plants to serve increasing load) [10]. Thus, stagnant or declining sales as a result of DPV, as well as energy efficiency [11] and other forms of other forms of distributed energy resources (DERs), may reduce these future earnings opportunities [12]. Future growth in electric vehicle penetration, among other sources of electrification which increase electricity consumption, may counter the prevailing trend of declining sales.

Furthermore, the decrease in DPV and other forms of DER costs (e.g., battery storage) has led to increased financial pressure on the utility from customer self-supply [13]. Many utilities around the world typically allocate a significant portion of their fixed costs to volumetric energy charges. As a result, any reduction in electricity sales without a similar reduction in fixed costs erodes a utility's net revenues. Such impacts are especially disconcerting to utility shareholders due to the reduction in achieved earnings and return on equity (ROE) [14].

At the same time, utility regulators are increasingly concerned about possible increases in retail rates and cost-shifting from customers with DPV (i.e., participants) to non-DPV customers (i.e., non-participants) [15]. In instances where costs increase faster than sales, there is upward pressure on retail rates. In addition, customers who invest in DPV and can significantly reduce or even eliminate the volumetric portion of their bills via NEM may not adequately pay their full share of the utility's fixed costs, which places an increased cost burden on non-participating customers.

Regulators of any utility in such a situation must weigh utility and ratepayer concerns as they consider changes to NEM and retail rate design that directly affects DPV, battery storage, and other forms of DER. Ultimately, they must make a determination that they believe serves the broader public interest based on the information they have available to them.

While these concerns are qualitatively understood, there is a lack of empirical and quantitative analysis to bound the magnitude of these concerns and the efficacy of alternative utility regulatory and business models. Instead, most quantitative analyses evaluating DPV impacts on an electric utility exclusively focus on a simplified cost and/or benefit analysis without considering the financial implications on a utility [16]. Those studies which focus on DPV costs find incremental electric system costs which range from $\$ 0-25 / \mathrm{MWh}$ [17-24]. On the other hand, those studies which focus on DPV benefits find electric system benefits which range from \$0-53/MWh [25-32]. In general, these analyses focus on system costs and benefits without considering the role of a regulated utility and their accompanying business practices.

Another subset of the literature evaluates how NEM and DPV adoption impacts utility ratepayers but notably does not incorporate a fully-integrated pro forma financial model. Poulilkkas [33] studied the effect of NEM on DPV adoption at one representative household while Christoforidis et al. [34] performed a similar analysis across a broader set of 31 customers. Neither study evaluated the impact on electric utility collected revenues or earnings. Eid et al. [35] and Picciariello et al. [36] expanded on this work by evaluating the cross-subsidization due to NEM between PV owners and non-owners. Furthermore, Johnson et al. [37] added an analysis of the DPV impact on utility load shape into the analysis of NEM cross-subsidization between PV owners and non-owners. However, none of the above quantitative studies: (1) calculate utility shareholder impacts, (2) take into account regulatory lag and other artifacts of utility regulation (e.g., test years), or (3) integrate a long-term analysis horizon that incorporates feedback effects between PV hourly loads and utility costs that accumulate over time to impact electricity rates.

Many of the concerns expressed by utilities and regulators, though, depend critically on the specific changes in costs and revenues that are a function of utility cost compositions (e.g., proportion 
of fixed versus variable costs), physical system attributes (e.g., hourly loads), and fixed cost recovery mechanisms, among others, which interact with PV adoption and utility regulatory considerations over time. Most of the prior studies reviewed above do not perform a comprehensive financial analysis using these key utility characteristics and do not incorporate a robust review of the costs and benefits of DPV in retail electricity rates.

To fill this research gap, this study quantifies the financial impacts of net-metered DPV on a prototypical Western U.S. IOU and identifies the key sensitivities driving lesser or greater magnitude of impacts. While we integrate the above cost-benefit studies into our financial modeling, we use a financial framework that better assesses the implications for a regulated IOU. Furthermore, we build on prior quantitative analysis of the financial impacts of net-metered PV [38,39] by assessing a wider range of sensitivities specific to the ability of DPV to avoid or defer utility costs (i.e., "DPV value"). Although the costs, revenue, and regulatory accounting assumptions are based on the U.S. context, we believe the results are generalizable and relevant for other utility circumstances around the world.

\section{Materials and Methods}

We quantify the shareholder and ratepayer impacts for a Western U.S., vertically-integrated IOU (i.e., that owns generation, transmission, and distribution assets) at two DPV deployment levels (i.e., $4 \%$, and $8 \%$ of 2027 retail sales) representing the range of forecasted DPV deployment among Western states [40] using a proprietary pro forma financial model.

The FINancial impacts of Distributed Energy Resources (FINDER) pro forma financial model quantifies the utility's annual costs and revenues over a pre-defined analysis period. See Appendix A for a more detailed description of the pro forma financial model used in this analysis. The model performs all cost calculations at the total utility level but has the ability to allocate those costs to different rate classes in order to assess differential revenue impacts. Key outputs include achieved ROE and earnings, average all-in retail rates and customer bills, which can be used by utilities, policymakers, customer groups, and other stakeholders when assessing the impacts and implications of policy proposals and decisions.

Because the model derives customer class level ratepayer metrics, a more comprehensive bill impact analysis across different customer types, which assumes different hourly consumption profiles for customers and different DPV production profiles for participants, was not possible. A number of other studies have sought to quantify participant and/or non-participant bill impacts in substantial detail, but without any associated feedback effects on rates [41-43]. However, our estimates of the percentage change in average all-in retail rates can be used as a proxy for the percentage change in a non-participants' bill assuming there are no associated changes in their electricity consumption.

Results of our analysis using this pro forma financial model are compared against a case without DPV, incremental energy efficiency, or other DERs in order to isolate the DPV impacts. The DPV is installed linearly over ten years to reach its terminal deployment level (as a percentage of retail electricity sales) with impacts measured over 20 years to capture utility system economic end-effects (i.e., cost avoidance or deferral). We limit our analysis to 20 years despite DPV system lifetimes in excess of 20 years due to the effects of discounting costs and revenues, in addition to increasing uncertainty in utility cost and load forecasts. We also assess the sensitivity of impacts to different assumptions about the "DPV value" (i.e., ability of DPV to avoid or defer utility costs). Each of these different cases are discussed in more detail below.

\subsection{Prototypical Western Utility Characterization-Base Case}

We developed a 20-year cost and load forecast for a prototypical Western utility by starting with the 2014 general rate case filing of Public Service of Colorado. The general rate case filing was the most recent for the utility that included a cost-of-service study and provided reasonable starting year cost levels, starting year class-level retail sales, peak demand, and customer counts, and class-level cost allocation and rate design. Growth in retail sales, peak demand, and customers are based on Public 
Service of Colorado's 2016 integrated resource plan (IRP), which was the most recent one available. Growth in utility cost categories, specifically generation capital expenditures (CapEx), distribution CapEx, and operations and maintenance $(\mathrm{O} \& \mathrm{M})$, are based on historical 5-year average annual growth rates among Western utilities derived from their FERC Form 1 filings. Last, the Western utility's hourly load shape is based on Public Service of Colorado's 2017 hourly load (reported in EIA Form 930) and we used a simple average of load in hours before and after missing values to derive a complete 8760-h load shape. Importantly, while many of the input assumptions were seeded with a single utility's data, the utility in this analysis is not meant to represent Public Service of Colorado specifically.

We refer to four key assumptions in the Western utility characterization when describing financial impacts. First, non-fuel costs (inclusive return of (i.e., depreciation) and on capital investments, fixed O \& M, interest expense, and taxes) grow by 3.3\% per year over the 20-year analysis period (2018-2037) (see Figure 1). Western utilities have seen median generation, transmission, and distribution CapEx costs increase by $6.4 \%, 3.6 \%$, and 3.8\% per year from 2012 to 2016, respectively (calculated based on utility FERC Form 1 data), and we assume similar, rounded CapEx cost escalations (i.e., $6 \%$, $4 \%$, and $4 \%$ annual growth in generation, transmission and distribution CapEx costs, respectively). Utility fuel and purchased power (energy and capacity) costs grow by $2.6 \%$ per year over the same 20-year analysis period. Our fuel and purchased power costs for non-renewable generation technologies are based on EIA fuel, heat rate, and variable O \& M cost assumptions [44]. Wind and solar PPA costs are based on NREL's Annual Technology Baseline LCOEs in the "Wind TRG 4" and "Solar CF 20\%" forecasts [45].

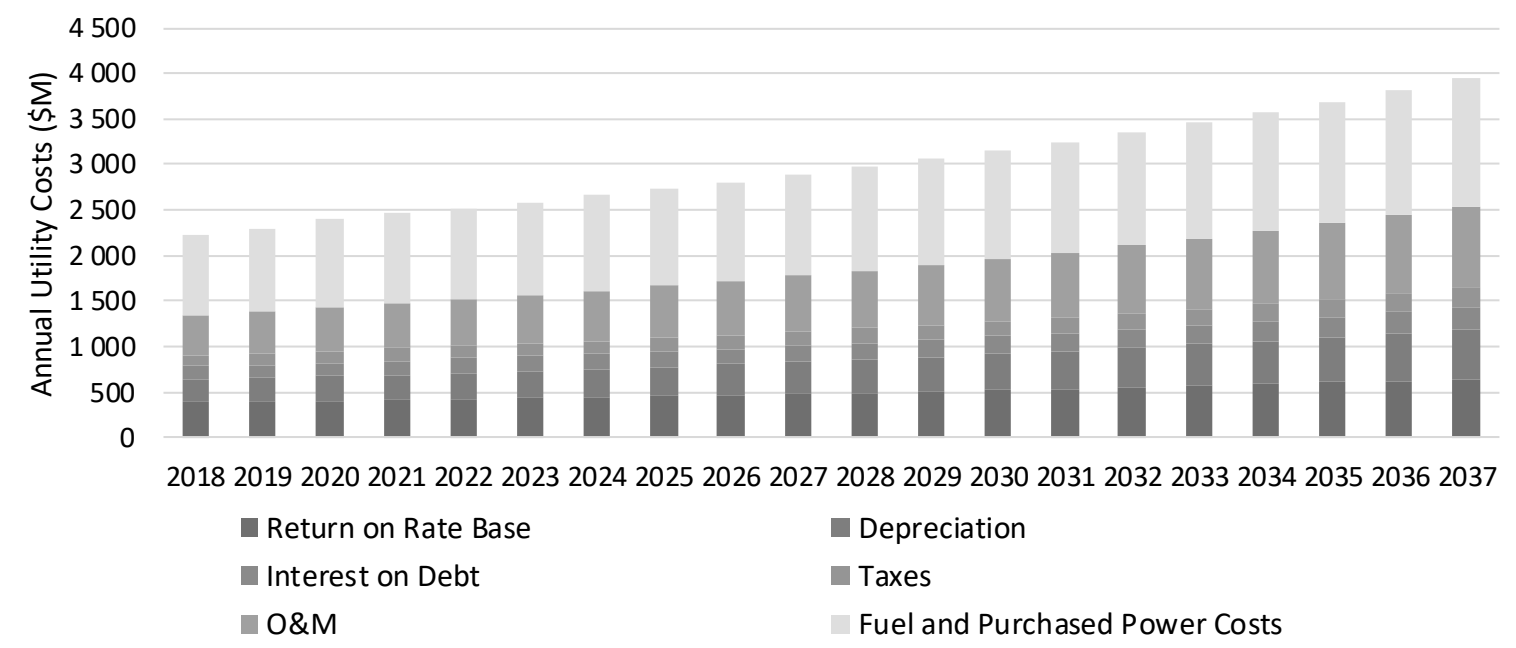

Figure 1. Forecasted Western utility costs (without DPV).

Second, the Western utility's retail sales grow by about $1.0 \%$ per year and annual peak demand grows by about $0.9 \%$ per year. Our load growth assumptions are based on a specific utility's IRP forecasts in order to match any incremental generation or purchased power, though the retail sales forecasts are higher than historical, median sales growth among Western utilities. From 2012 to 2016, Western utility median sales slightly declined by about $0.3 \%$ per year based on EIA- 861 data.

Third, we assume no incremental generation additions in the Base case analysis, as Public Service of Colorado is forecasting PPAs to meet incremental load in its 2016 IRP. We make this assumption about no incremental generation additions in order to maintain consistency between our load and cost assumptions. Given that Western utilities averaged flat, or declining, load growth over the last 5-years, we believe our assumption is reasonable. Nevertheless, we consider the case of incremental generation additions in our sensitivity analysis. We also assume retirement of three generating units during the 20-year analysis period to maintain consistency with Public Service of Colorado's IRP loads and resources table. These are all input assumptions used to develop a pro forma revenue requirement and were not derived as part of a system planning module within FINDER. As such, the impacts of DPV 
on utility capital costs are based on a coarser set of assumptions than might be possible with planning models representing the utility's generation dispatch and power flows on distribution feeders.

Fourth, we assume a flat retail rate design for all customer classes (as opposed to inclining block or time-of-use rates). Residential customer rates and bills collect $90 \%$ of revenues via volumetric energy rates with the remainder of revenues $(10 \%)$ collected via a monthly, fixed customer charge. Commercial and industrial (C \& I) customer rates and bills collect about $40 \%$ of revenues via an energy charge, $55 \%$ of revenues via a demand charge (based on class monthly non-coincident peak), and the remaining via a fixed, monthly customer charge.

\subsection{Alternative Assumptions in Utility Characterization-Sensitivity Cases}

We developed a set of cases to better understand the sensitivity of shareholder and ratepayer impacts from DPV to assumptions related to its capacity value and avoided generation, transmission, and distribution costs. These sensitivity cases involved modifying a number of parameters from the Base case (see Figure 2), based on ranges that exist in either the literature or Western utility historical data.

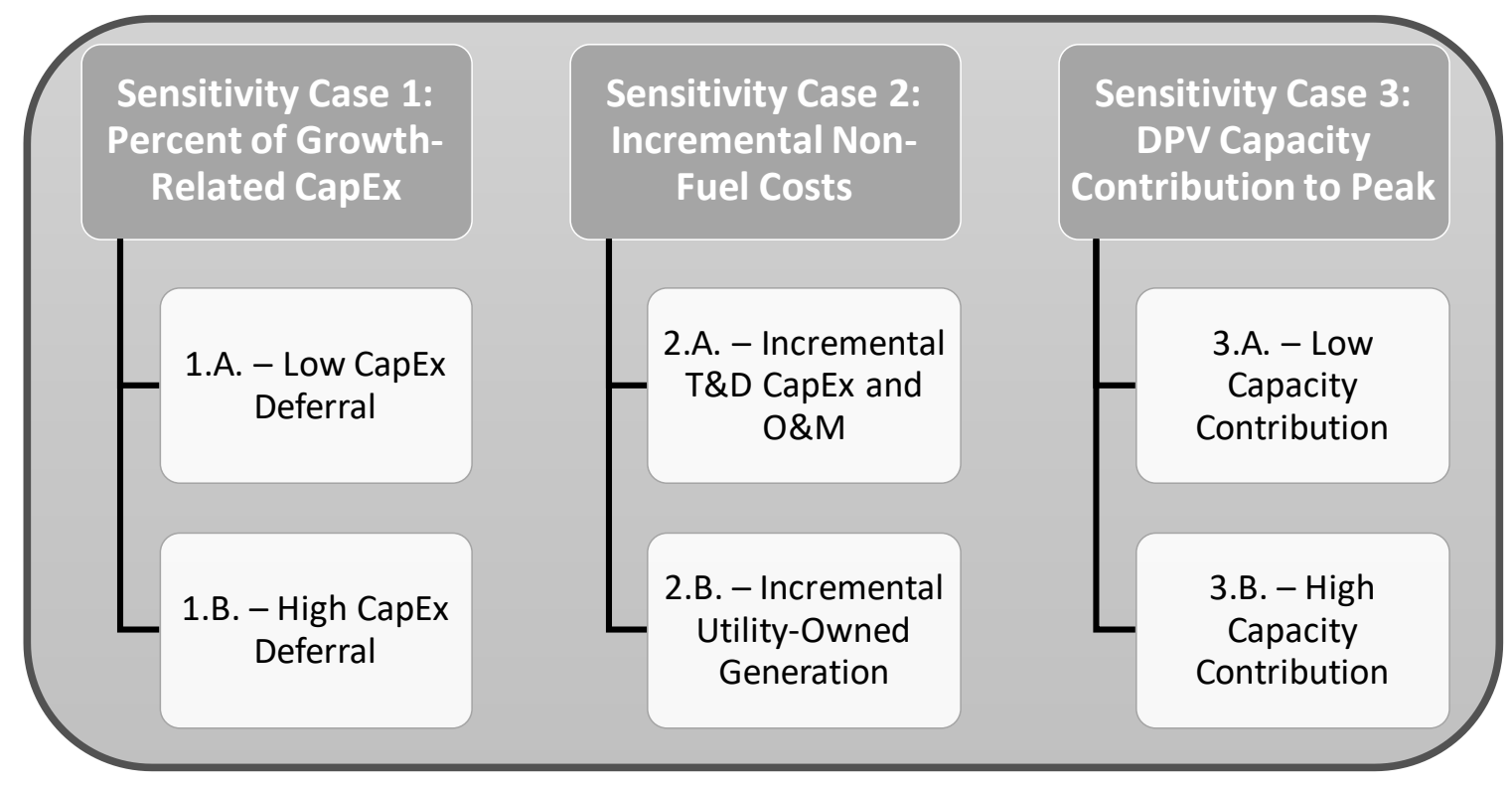

Figure 2. Modeled sensitivity cases among three key assumptions related to DPV value.

In our first sensitivity case, we change the assumed percent of transmission and distribution (T \& D) CapEx that are growth-related. As previously discussed, we model two categories of T \& D CapEx: load growth-related and non-load growth-related. The Base Case assumes a portion (33\%) of investments are growth-related CapEx and the addition of DPV reduces this growth-related CapEx proportional to reductions in annual peak demand. The $33 \%$ assumption is consistent with assumptions in prior studies $[38,39,46]$. This results in corresponding reductions in returns on ratebase, depreciation expenses, interest, and taxes For the sensitivity case, we bound the assumption with a low value of $10 \%$ growth-related T \& D CapEx (i.e., Sensitivity Case 1.A.) and high value of $90 \%$ growth-related T \& D CapEx (i.e., Sensitivity Case 1.B.). Appendix B shows the sensitivity case analysis results as change in DPV value, change in achieved earnings, and change in average all-in retail rates.

In our second sensitivity case, we change assumptions related to incremental CapEx. In one case, we increase distribution CapEx and O \& M costs in conjunction with DPV to represent the possibility that integration costs for DPV could result in a net increase in distribution system expenditures (i.e., Sensitivity Case 2.A.). For the purposes of our study, system integration costs are borne by the utility (and all ratepayers via retail rates) and are different from interconnection costs that are paid by DPV owners. We assume incremental distribution O\&M cost of $\$ 15 / \mathrm{kW}$-year installed DPV [47] 
and incremental distribution CapEx of $\$ 30 / \mathrm{kW}$ installed DPV [48]. Alternatively, we add incremental utility generation to meet future capacity needs motivated by the fact that some Western utility DPV value studies assumed deferred generation (i.e., Sensitivity Case 2.B.). As discussed in Section 2.1, the Base case utility characterization assumes the Western utility meets future capacity and energy through PPAs and short-term market purchases (as is consistent with the IRP data we used as the basis for our Western utility characterization). We base this sensitivity case on a simple loads and resources table and add mid-merit and natural gas generating plants in 100MW and 250MW increments to meet forecasted peak demand in the Base case without DPV. Capital and O \& M costs of the incremental generation are based on EIA overnight capital cost estimates for generating plants and inflated at $2 \%$ per year.

In our third sensitivity case, we change the amount of DPV coincident with the Western utility's annual peak demand (i.e., capacity contribution to peak). The Base case assumes a $22 \%$ DPV capacity contribution to peak (discussed in the next section). We bound this assumption with a lower value of $12 \%$ (i.e., Sensitivity Case 3.A.) and higher value of 32\% (i.e., Sensitivity Case 3.B.). The DPV capacity contribution to peak drives the reduction in annual system peak demand upon which capacity and $\mathrm{T}$ \& D CapEx costs are based. Thus, an increase in DPV capacity contribution to peak would result in greater avoided capacity-driven costs at the same DPV deployment level.

\subsection{DPV Characterization}

Our pro forma financial model derives the impacts of DPV through several key static and dynamic interrelationships. DPV impacts utility billing determinants; specifically retail sales and peak demand, which has an effect on utility costs and subsequently retail rates. DPV reduces volumetric sales based on a direct relationship between the assumed annual DPV penetration, expressed as a percentage of annual sales on a customer-class basis, and the utility's class-level sales. The model derives reductions in the utility's peak demand through dynamic relationships of several variables that take into account: (1) the specific timing of DPV relative to the utility's hourly load, and (2) potential differences in alignment between when the DPV causes reductions in the utility's load and the utility system annual peak demand.

The timing of DPV production (savings) and the utility annual peak demand is a key driver in the analysis. DPV reduces energy only in hours when the PV system operates (i.e., during the daylight hours) and may also reduce utility system demand depending on whether the reduction in energy is coincident with the utility's system peak. Thus, the timing of DPV energy and demand savings in relation to customer class and utility peak demands (monthly and annual) drives projections of future costs, retail rates, and revenues collected on a volumetric basis through energy and demand charges.

To calculate the DPV shape, we relied on the National Renewable Energy Laboratory's (NREL) System Advisor Model (SAM) [49]. We simulated five solar profiles with typical meteorological year (TMY) weather data for different locations in Colorado's main metropolitan areas (i.e., Boulder, Aurora, Denver, Colorado Springs, and Pueblo). These simulations relied on PV Watts default assumptions (i.e., azimuth of 180 degrees, DC to AC ratio of 1.2, and tilt of 40 degrees). To estimate a single input profile for our pro forma financial model, we applied a population-weighted average solar output of the five metro area's solar shapes.

We further analyzed DPV's capacity contribution to peak load reduction by simulating DPV profiles using 2017 weather data. While the TMY weather data described above provides an ideal average profile, it does not provide an understanding of DPV's contribution to peak load reduction for our underlying load year of 2017. To determine this value, we simulated the additional solar profiles and sampled the capacity factor of our DPV simulation in the top-20 load hours of 2017 for Public Service of Colorado. The resulting capacity contribution to the top-20 load hours was $22 \%$. DPV capacity factors are often calculated based on probabilistic simulation and modeling methods such as Effective Load Carrying Capability (ELCC), however, carrying out such a simulation is not the focus of this study; alternatively, we quantify DPV capacity contribution as the percentage of 
the nameplate capacity that is available during top-20 load hours; this factor provides a simple and intuitive measure of the value provided by DPV in terms of capacity and can be represented in our pro forma financial model. This value became our Base Case capacity contribution to peak load reduction for DPV. We performed this analysis for a number of other Western utilities and found that this capacity value in the top- 20 load hours ranged from $7 \%$ to $26 \%$, which we use to inform our sensitivity cases discussed above.

The DPV portfolios reduce the Western utility's annual retail sales and peak demand. Retail sales grow by $1.0 \%$ per year in the case without PV, but the annual growth rate declines to $0.6 \%$, and $0.2 \%$ in the 4\% and 8\% DPV deployment cases, respectively, from 2018 to 2027 as DPV systems are installed. Because the DPV penetration levels are specified in terms of a percent reduction of retail sales, they each reduce the Western utility's sales on a one-for-one basis. As shown in Figure 3, the reduction in retail sales increases as the DPV deployment level increases.

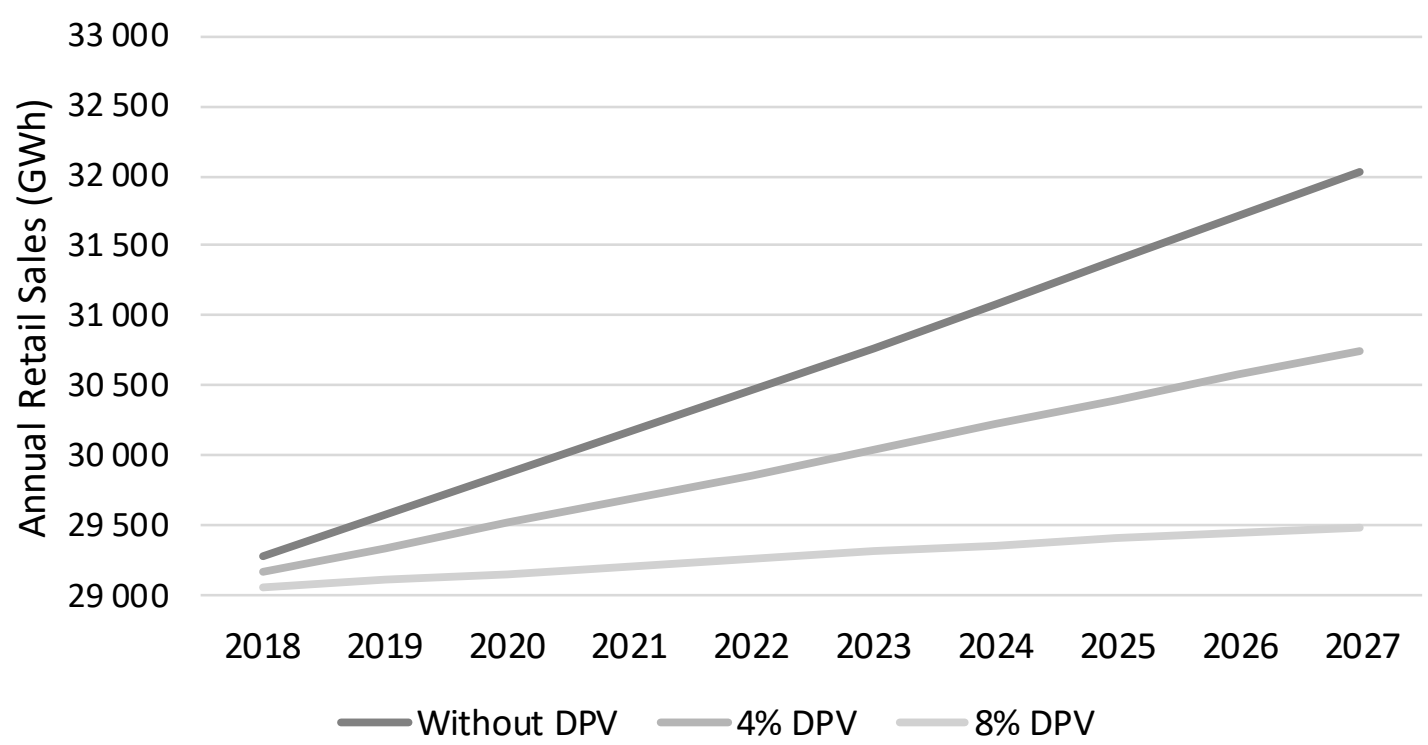

Figure 3. Forecasted Western utility annual retail sales without DPV and at increasing DPV deployment levels ( $4 \%$ and $8 \%$ of 2027 retail sales).

The impacts of DPV on the Western utility's annual peak demand depends on the timing and coincidence of DPV relative to the utility's annual peak demand. Figure 4 shows the forecasted annual peak demand for the Western utility from 2018 to 2027 and the coincident peak demand savings attributable to the DPV deployment cases. The prototypical Western utility modeled in this study has peak loads that occur in July generally between 2 p.m. and 6 p.m. prior to the addition of DPV systems. The coincident peak demand impact of DPV in our study is less than the retail sales impacts on a percentage basis (e.g., $0.8 \%$ per year reduction in retail sales and $0.6 \%$ per year reduction in peak demand in the $8 \%$ DPV deployment case) because the timing of maximum PV output does not coincide perfectly with the utility's annual peak demand. This is particularly the case for Public Service of Colorado that serves load near the Rocky Mountains, which results in lower DPV production in afternoon hours relative to other geographic locations due to the effect of mountain shadows [50]. We consider lower and higher contribution of DPV savings to peak in the DPV value sensitivities. 


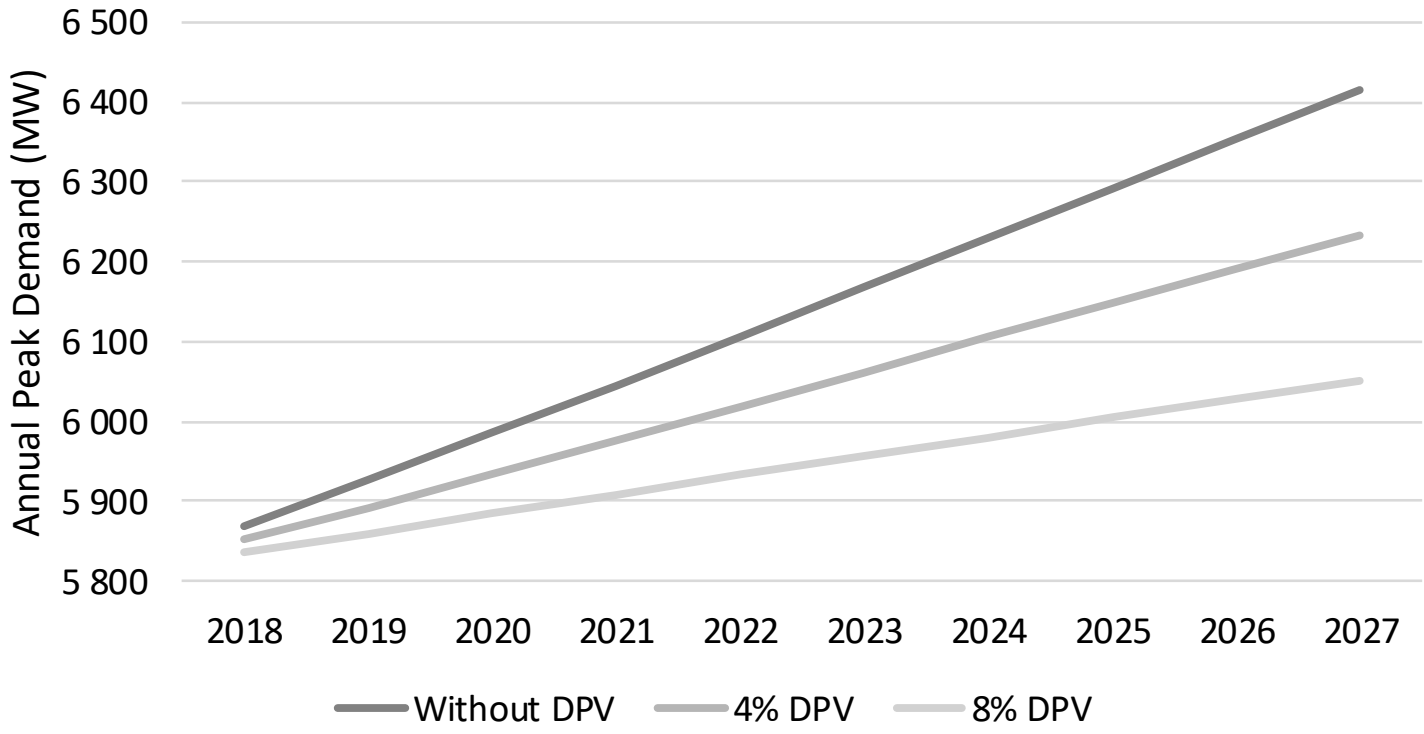

Figure 4. Forecasted Western utility annual peak demand without DPV and at increasing DPV deployment levels ( $4 \%$ and $8 \%$ of 2027 retail sales).

\section{Results}

\subsection{Sensitivity of DPV Value to Alternative Utility Assumptions}

Figure 5 shows the change in DPV value with Base and alternate assumptions of the proportion of T \& D CapEx that is growth-related (i.e., Sensitivity Case 1.A. and 1.B.). A lower proportion of growth-related T \& D CapEx results in a lower DPV value, and vice-versa, where the change in value occurs exclusively among non-fuel cost categories. In the 4\% DPV deployment case, the DPV value ranges from $\$ 51 / \mathrm{MWh}$ to $\$ 57 / \mathrm{MWh}$ and, in the $8 \%$ DPV deployment case, the DPV value ranges from $\$ 50 / \mathrm{MWh}$ to $\$ 55 / \mathrm{MWh}$. The modeled DPV value results are not particularly sensitive to this assumption, ranging from $-4 \%$ to $6 \%$ relative to the Base Case assumption.

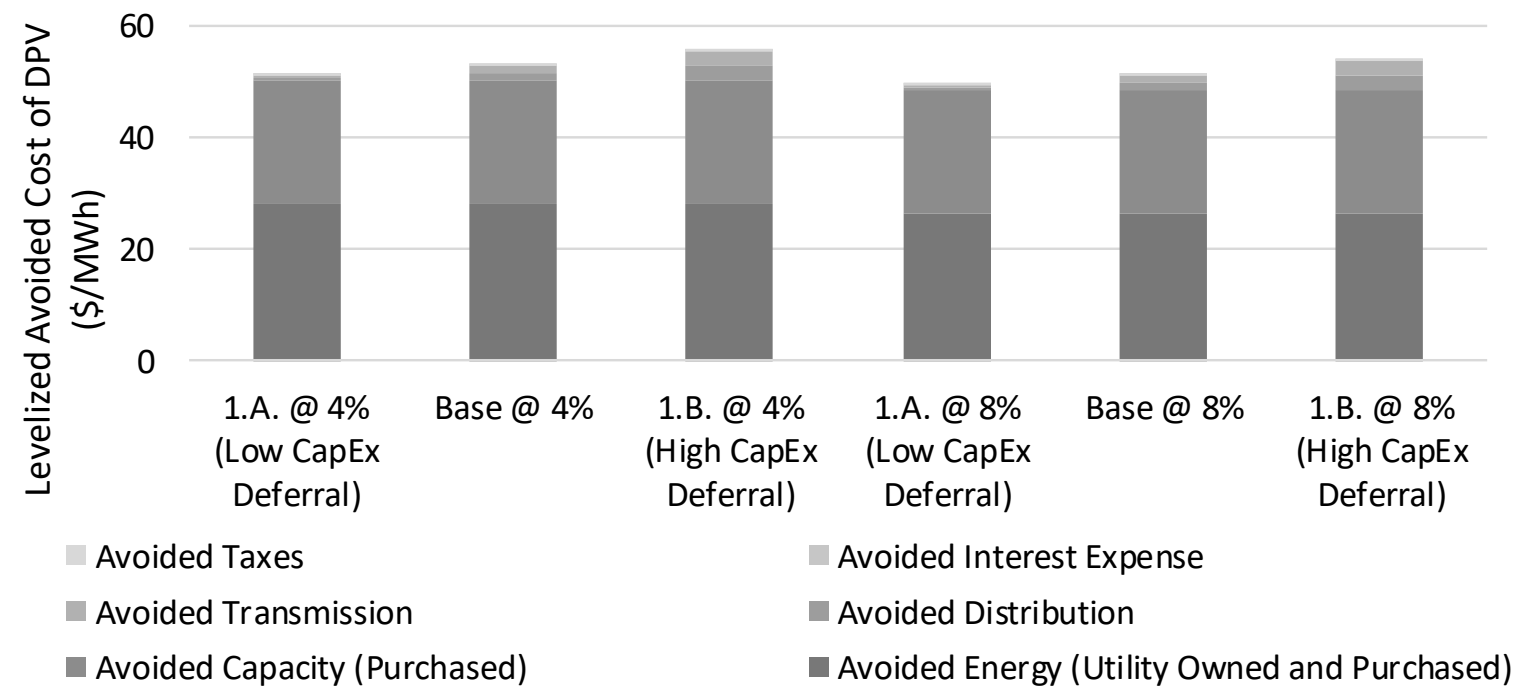

Figure 5. Sensitivity of DPV value to assumed proportion of growth-related CapEx.

Figure 6 shows the change in DPV value assuming incremental distribution and generation CapEx and distribution $O \& M$ costs to the Base Case (i.e., Sensitivity Case 2.A. and 2.B.). The incremental distribution CapEx and O \& M costs (i.e., Sensitivity Case 2.A.) do not result in additional value, as the costs are added incrementally with the installed DPV and counteract many of the avoided costs. 
Thus, the DPV value declines significantly in both the $4 \%$ DPV and $8 \%$ DPV deployment cases. In fact, DPV value at $8 \%$ deployment and assuming incremental distribution CapEx and O \& M is roughly half of the Base Case DPV value ( $\$ 27 / \mathrm{MWh}$ compared to $\$ 52 / \mathrm{MWh}$ ). The incremental utility generation assumption (i.e., Sensitivity Case 2.B.) reduces the avoided purchased capacity value, as would be expected due to the incremental generation installed in lieu of the capacity purchases. Also, as to be expected, the proportion of CapEx deferral value increases as the DPV defers or avoids some of the incremental generation. In total, however, the DPV value in the incremental utility generation case is about $10 \%$ lower than the Base Case assumption because the cost of utility-owned generation is lower relative to meeting the same capacity needs through PPAs and short-term market purchases. Thus, the incremental utility generation sensitivity case produces a lower total DPV value.

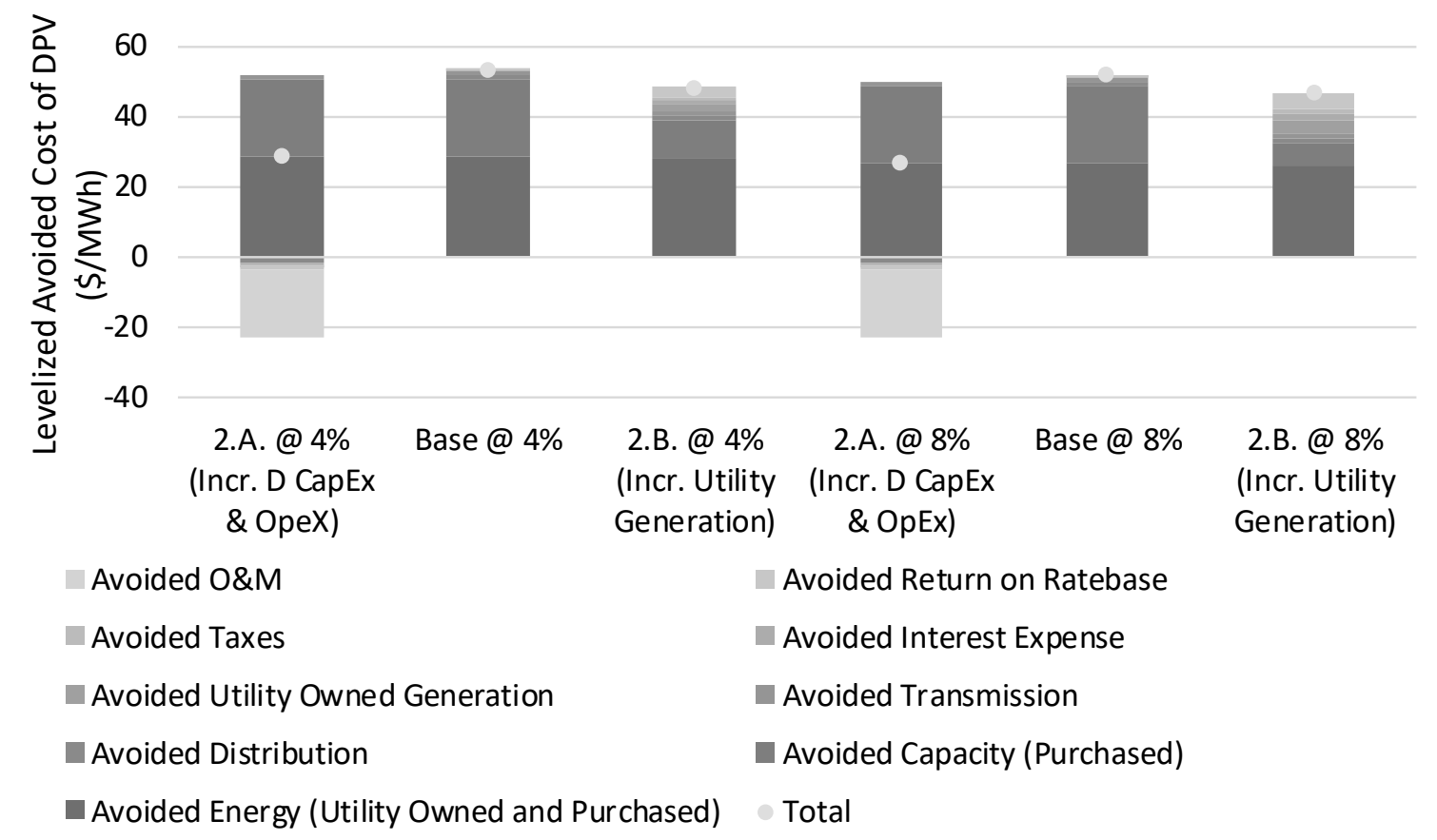

Figure 6. Sensitivity of DPV value to incremental non-fuel costs.

Figure 7 shows the change in DPV value with lower or higher assumed DPV capacity contribution to peak relative to the Base Case assumptions (i.e., Sensitivity Cases 3.A. and 3.B.). As expected, a lower capacity contribution to peak (i.e., Sensitivity Cases 3.A.) results in lower DPV value, and vice-versa, with the largest change in avoided capacity purchases. In the $4 \%$ DPV deployment case, the DPV value ranges from $\$ 42 / \mathrm{MWh}$ to $\$ 59 / \mathrm{MWh}$ and, in the $8 \%$ DPV deployment case, the DPV value ranges from $\$ 40 / \mathrm{MWh}$ to $\$ 54 / \mathrm{MWh}$. The modeled DPV value results are quite sensitive to this assumption, ranging from $-27 \%$ to $11 \%$ relative to the Base Case assumption. The results for all sensitivity cases show that DPV value is sensitive to alternate assumptions, but the degree depends on the specific assumption. For example, the assumed proportion of growth-related CapEx (i.e., Sensitivity Case 1.A. and 1.B.) has a small range whereas the DPV capacity contribution to peak (i.e., Sensitivity Case 3.A. and 3.B.) exhibits a much larger range of results. 


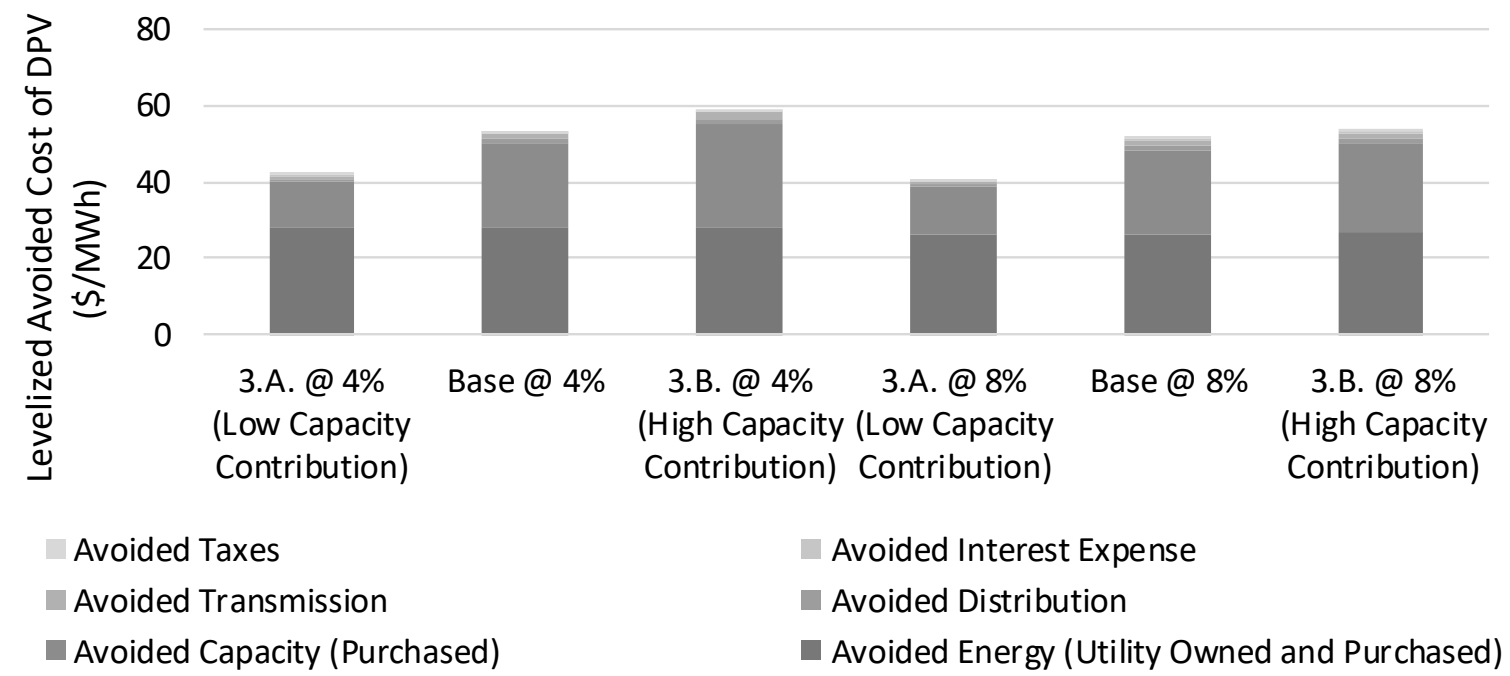

Figure 7. Sensitivity of DPV value to assumed DPV capacity contribution to peak.

Importantly, we did not combine changes in more than one key assumption, which would likely drive greater change in DPV value than is observed in isolated cases (e.g., combine higher DPV capacity contribution to peak with higher CapEx deferral which would likely leader to greater DPV value).

\subsection{Sensitivity of Shareholder and Ratepayer Metrics to Alternative Utility Assumptions}

As shown in Figures 8 and 9, the impacts of DPV on shareholder earnings and ROE vary under these different assumptions related to the penetration of DPV and the value of DPV to the utility. In the Base Case, the after-tax earnings achieved by the Western utility decline as the DPV deployment level increases $(1.5 \%$ reduction at $4 \%$ DPV and $3.1 \%$ reduction at $8 \%$ DPV) while its achieved average ROE declines as the DPV deployment level increases (1.6\% reduction at $4 \%$ DPV and $3.2 \%$ reduction at $8 \%$ DPV) compared to the case without DPV. Adding incremental distribution CapEx and distribution O\&M costs (i.e., Scenario 2.A.), or substituting PPAs with utility generation (i.e., Scenario 2.B.) alters the utility's non-fuel cost assumptions directly and, therefore, produce the most significant change in shareholder impacts. Across the range of sensitivity cases at $8 \% \mathrm{DPV}$, earnings impacts range from a 3.0\% reduction (i.e., Scenario 1.B) to a $4.8 \%$ reduction (i.e., Scenario 2.A.), and ROE impacts range from a $2.8 \%$ reduction (i.e., Scenario 2.B) to a $5.4 \%$ reduction (i.e., Scenario 2.A) compared to the case without DPV (on a percentage, not absolute, basis).

Importantly, these percentage reductions are against small reductions in earnings and ROE on an absolute basis. For example, achieved earnings decline by $\$ 123 \mathrm{M}$ (20-year present value) in the $8 \%$ DPV Base case out of a total earnings basis of \$3.96B (20-year present value). Even with DPV value assumptions driving the most impactful change in earnings that assume incremental distribution CapEx and O \& M (i.e., Scenario 1.A.), the absolute reduction in earnings is $\$ 190 \mathrm{M}$ (20-year present value). The same is true for achieved average ROE impacts that are a 25 basis-point reduction at $8 \%$ DPV in the Base Case. The reduction in achieved ROE assuming incremental distribution CapEx and $\mathrm{O} \& \mathrm{M}$ (i.e., Scenario 1.A.) is 42 basis points. 


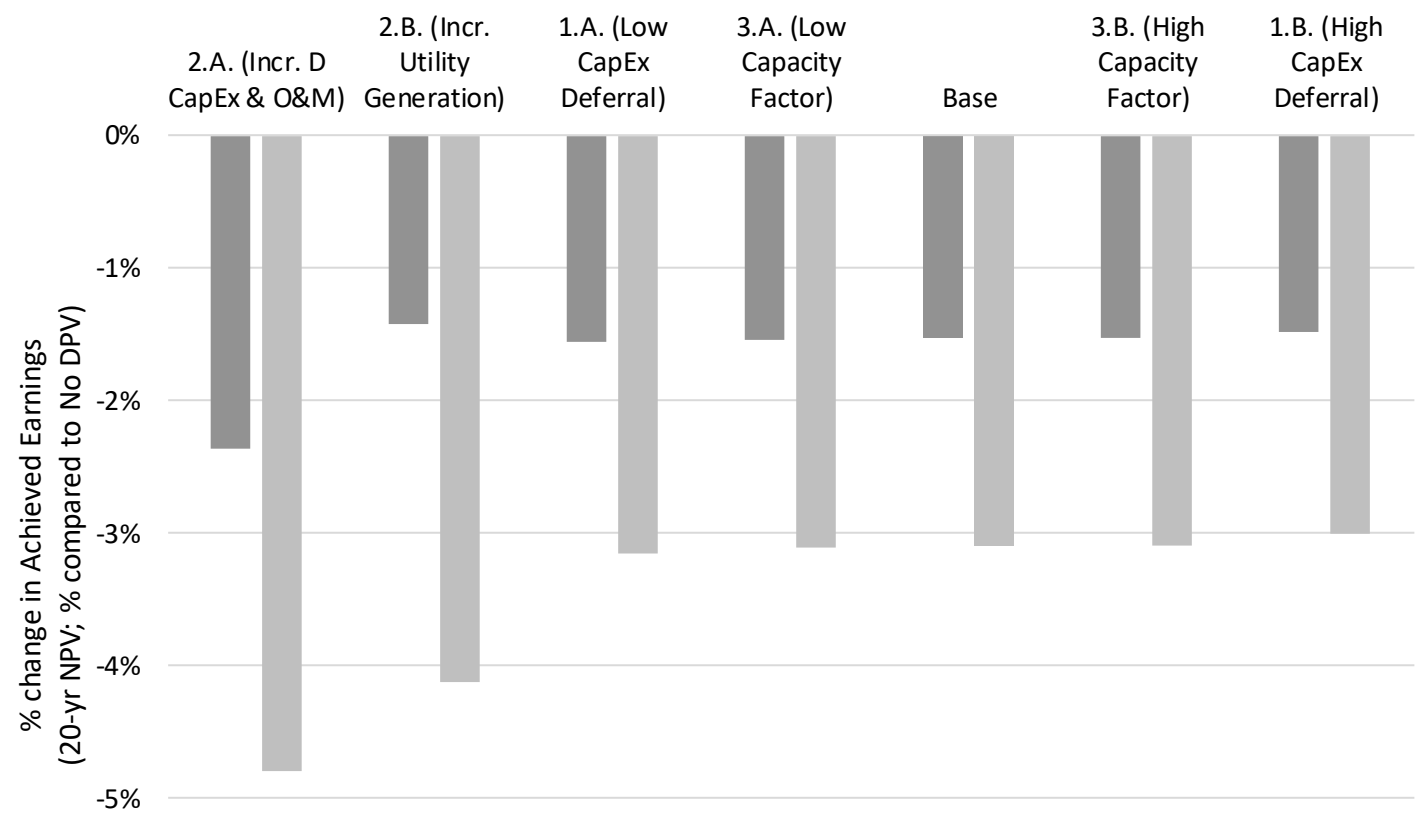

$-6 \%$

4\% DPV $\quad 8 \%$ DPV

Figure 8. Sensitivity of Western utility achieved earnings to assumptions related to DPV value.

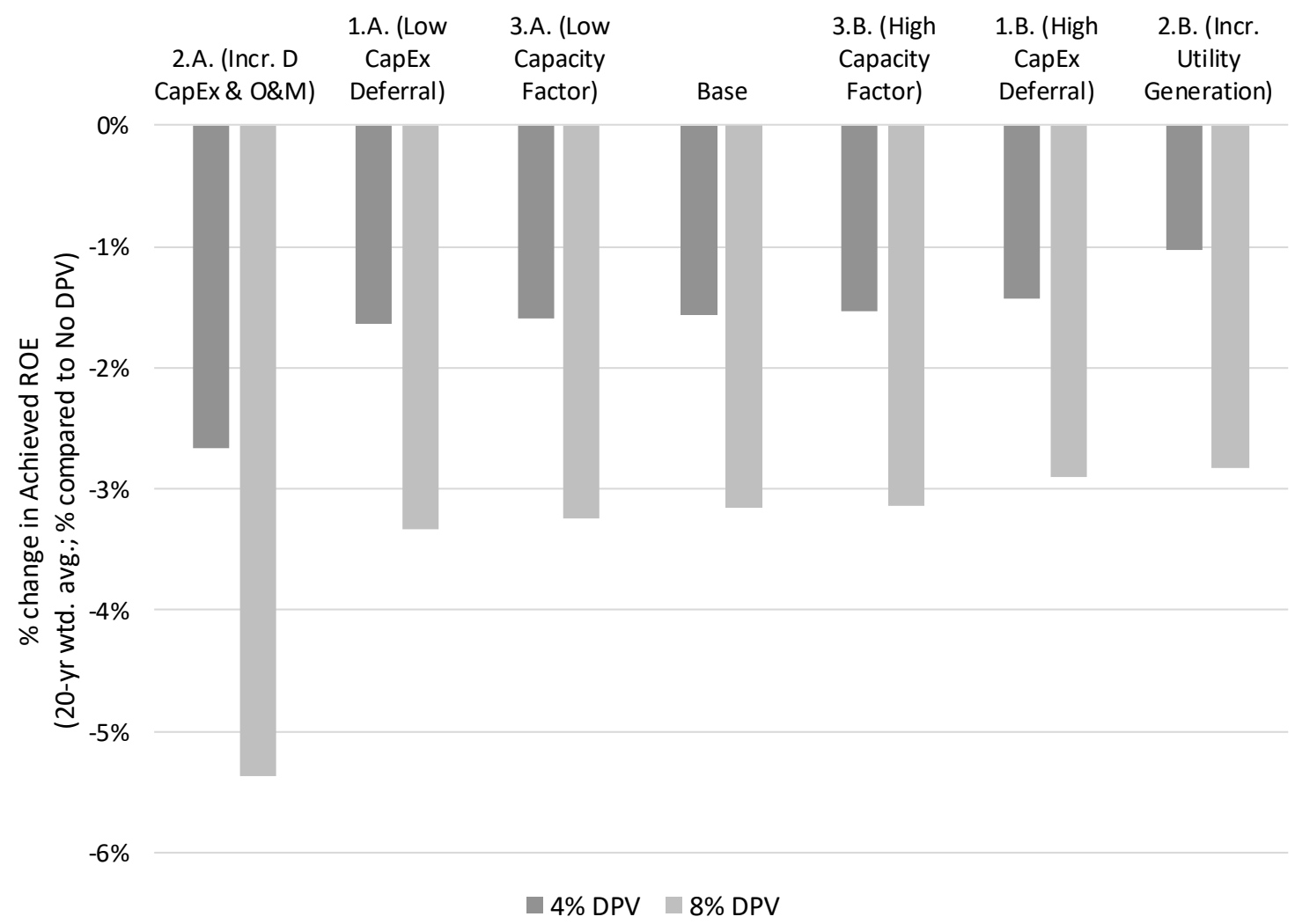

Figure 9. Sensitivity of Western utility achieved average ROE to assumptions related to DPV value.

As shown in Figures 10 and 11, the impacts of DPV on average all-in retail rates and customer bills vary under these different assumptions related to the penetration of DPV as well as the value of 
DPV. In the Base Case, the Western utility's all-in average retail rate increases as the DPV deployment level increases (1.1\% increase at $4 \%$ DPV and a $2.4 \%$ increase at $8 \%$ DPV); however the reduction in sales associated with DPV exceeds the impact from the rate increase, resulting in a decline in total customer bills ( $1.8 \%$ reduction at $4 \%$ DPV and a $3.6 \%$ reduction at $8 \%$ DPV). Relative to the case without DPV, assumptions driving greater cost deferral (regardless of fuel and purchased power costs or CapEx-related costs), result in lower ratepayer impacts (i.e., lower average rate impacts and greater total customer bill reductions). Across the range of sensitivity cases at $8 \% \mathrm{DPV}$, average retail rate impacts range from a $2.3 \%$ increase (i.e., Scenario 1.B.) to a $3.4 \%$ increase (i.e., Scenario 2.A.) and total customer bill impacts range from a $2.6 \%$ reduction (i.e., Scenario 2.A.) to a $3.7 \%$ reduction (i.e., Scenario 1.B.) compared to the Base case without DPV. Importantly, these bill savings reflect the aggregate impact across all customers and do not reflect the distribution of customer bill impacts among participating and non-participating customers. However, for non-participants who are not assumed to change their electricity consumption across scenarios, the reported percentage changes in average all-in retail rates is a proxy for their associated bill impacts.

Like the shareholder impacts, though, the percentage reductions are against small changes in ratepayer metrics on an absolute basis. Specifically, average all-in retail rates increase by $0.22 \mathrm{cents} / \mathrm{kWh}$ in $8 \%$ DPV Base Case and by 0.32 cents/kWh with DPV value assumptions with the most impactful change in average all-in retail rates (i.e., Scenario 2.A.). These changes compared to an average all-in retail rate of 9.20 cents/kWh (20-year present value) without DPV in the Base case. Similarly, there is a $\$ 1.31 \mathrm{~B}$ decrease in total customer bills (out of $\sim \$ 36 \mathrm{~B}$ basis) at $8 \%$ DPV. The total customer bill savings in the high CapEx deferral DPV value sensitivity (i.e., Scenario 1.B.) are $\$ 1.35 \mathrm{~B}$ at $8 \% \mathrm{DPV}$.

\begin{tabular}{|c|c|c|c|c|c|c|}
\hline $\begin{array}{l}\text { 2.A. (Incr. D } \\
\text { CapEx \& O\&M) }\end{array}$ & $\begin{array}{l}\text { 3.A. (Low } \\
\text { Capacity }\end{array}$ & $\begin{array}{l}\text { 2.B. (Incr. } \\
\text { Utility } \\
\text { Generation) }\end{array}$ & $\begin{array}{l}\text { 1.A. (Low } \\
\text { CapEx } \\
\text { Deferral) }\end{array}$ & Base & $\begin{array}{l}\text { 3.B. (High } \\
\text { Capacity }\end{array}$ & $\begin{array}{l}\text { 1.B. (High } \\
\text { CapEx } \\
\text { Deferral) }\end{array}$ \\
\hline & & & & & & \\
\hline
\end{tabular}

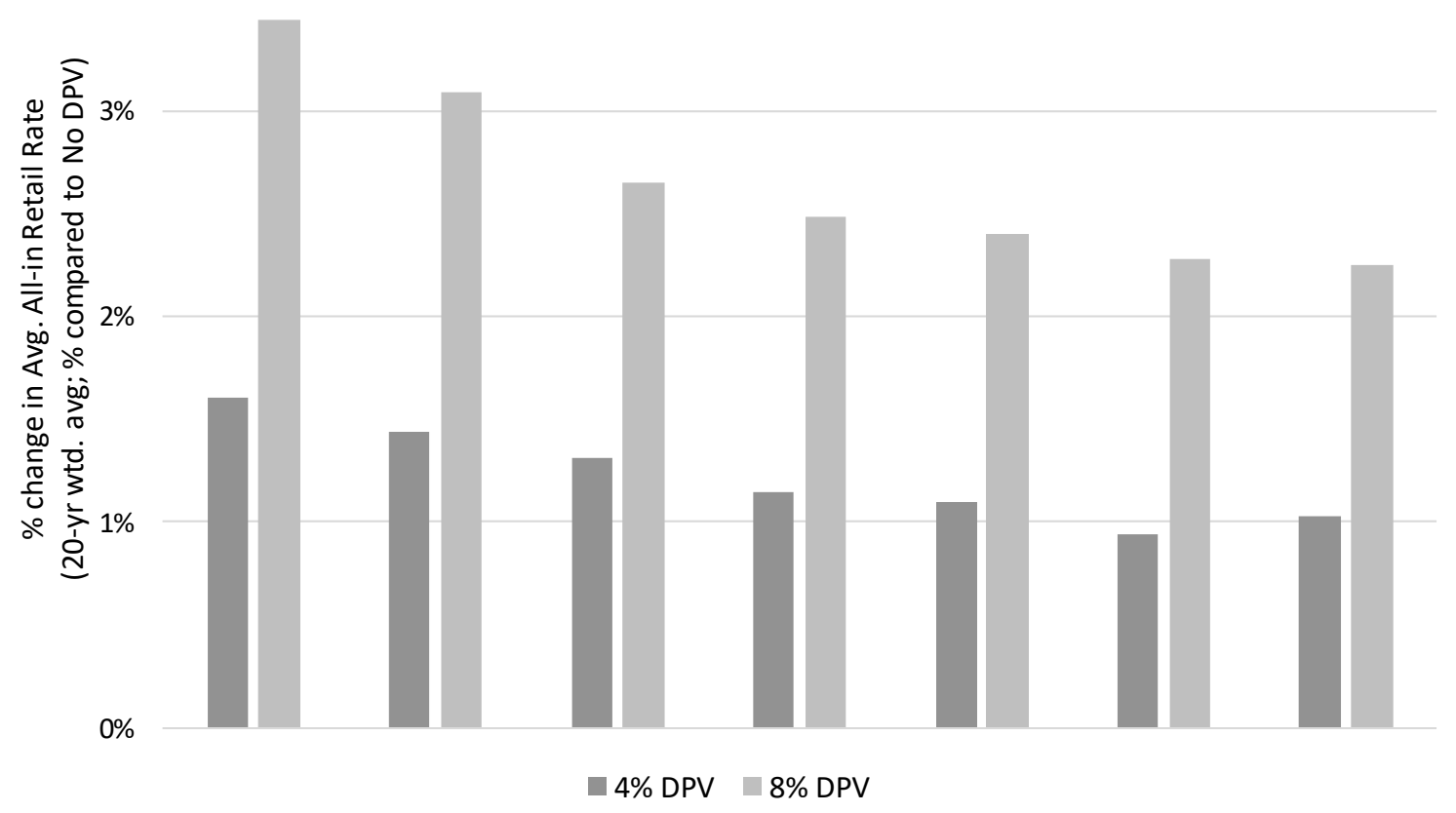

Figure 10. Sensitivity of Western utility average all-in retail rate to assumptions related to DPV value. 


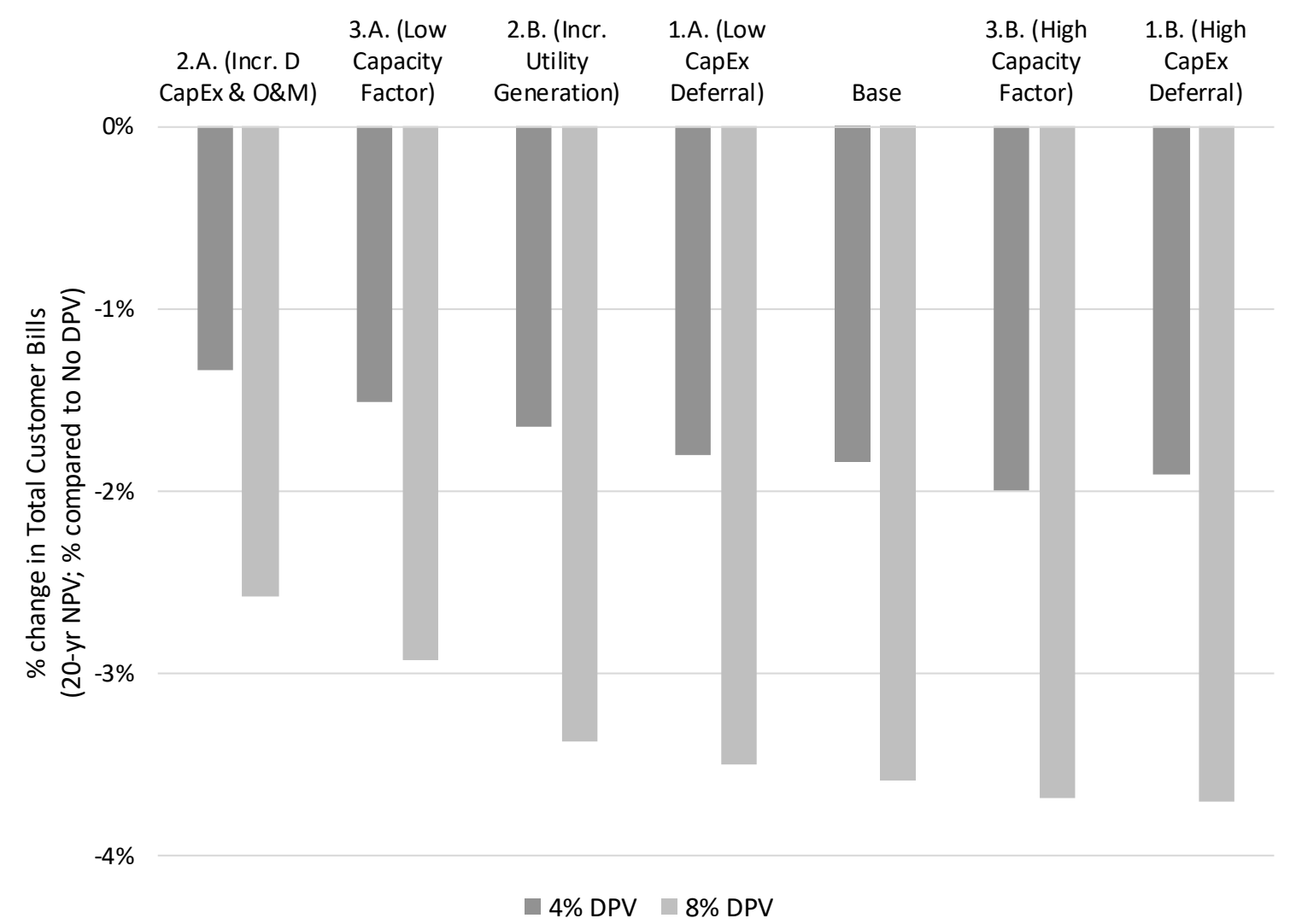

Figure 11. Sensitivity of Western utility total customer bills to assumptions related to DPV value.

\section{Discussion and Conclusions}

This analysis quantified the financial impacts of different levels of net-metered DPV deployment on a prototypical Western U.S. utility over 20 years and estimated changes in the utility's costs, revenues, achieved shareholder earnings and ROE, average all-in retail rates, and customer bills. We also quantified the sensitivity of results to different assumptions about the ability of DPV to avoid, defer, or increase utility fixed and variable costs.

Our analysis shows that DPV does in fact reduce utility achieved earnings, which occurs through two separate means. First, if DPV reduces utility revenues more than utility costs (as is likely under rate structures that recover the majority of utility costs via volumetric energy charges), then net revenues or earnings are likewise reduced (i.e., the "revenue erosion effect"). Second, and separately, DPV savings may also diminish future earnings opportunities by reducing the rate of growth or deferring capital investments (T \& D CapEx in our Base Case assumptions, specifically) that would otherwise contribute to the utility's ratebase (i.e., the "lost earnings opportunity effect"). Although our analysis does illustrate that the financial impacts on shareholders increase as the level of DPV deployment increases, the magnitude is small even at high DPV penetration levels (e.g., 2 to $4 \%$ change in financial metrics at $8 \%$ DPV deployment).

Our analysis also shows that net-metered DPV increases average all-in retail rates, which occurs in two, interrelated ways. First, DPV affects the retail rates set within each general rate case (GRC) through the net result of reductions in the test-year utility costs and billing determinants used to establish rates. DPV generally tends to reduce utility sales more than costs and, as a result, average retail rates established through each GRC increase with the addition of DPV in order to ensure the utility's rates collect sufficient revenue to recover authorized costs. Second, DPV affects average all-in retail rates in the years between GRCs, though this effect is simply a mathematical artifact. Average all-in rates are, by definition, equal to total collected revenues divided by total retail sales in any given year. Retail sales (i.e., the denominator) are reduced due to the incremental DPV. Because 
of these lower volumetric energy billing determinants, the revenues (i.e., the numerator) collected on an annual basis will also be reduced. However, the reduction in revenues are necessarily smaller than the reduction in retail sales, given that some portion of revenues are derived from fixed customer charges (which are unaffected by DPV) and demand charges (which are only marginally affected by DPV). Thus, DPV tends to increase average all-in retail rates in between GRCs as well. As with shareholder metrics, our analysis illustrates that ratepayer financial impacts increase as the level of DPV deployment increases, but the magnitude is small even at $8 \%$ DPV penetration levels.

We know that utilities in the Western U.S. are varied, and exist within dramatically different operating environments, face substantially different cost structures, and provide service to vastly different customer bases. To better understand the likely impacts of DPV on utilities in the West, and potentially extend the application of the results more broadly to other utilities around the world, this study also explicitly links different estimates of DPV value to shareholder and ratepayer impacts. Our analysis finds that even rather dramatic changes in DPV value result in modest changes to shareholder and ratepayer impacts. Also, the range of financial impacts under alternative DPV value assumptions are greater for shareholders than ratepayers on a percentage basis and driven by differences in the amount of incremental CapEx that is deferred, as well as the amount of incremental distribution O\&M that is incurred. The sensitivity cases reflect the key drivers of our results, but are not a complete list of all the sources of uncertainty and variation in modeled assumptions. There are other utility characteristics that might also change the magnitude and, in more extreme instances, the direction of impacts (e.g., higher or lower assumed load growth, higher or lower proportion of revenues from fixed charges, current or future test years). See [46] for the results of a number of sensitivity cases beyond the value of DPV. To be sure, the shareholder and ratepayer impacts presume no change in the underlying regulatory model or ratemaking approaches. More fundamental changes in the way electric utilities price energy services and recover fixed and variable costs may suggest different impacts than reported herein (e.g., see [51]). As such, our purpose here is not to bound the full range of impacts, but rather to illustrate some key themes and considerations related specifically to DPV value.

It is worth noting two particular feedback effects that our pro forma financial model does not account for in the present study and that would have potential implications for our results. First, we do not represent the feedback effects between retail rate impacts and DPV adoption rates. An increase in retail rates will improve the economics of DPV investment to customers (i.e., lower payback time for PV system) which, all else being equal, would be expected to drive greater PV adoption and thus lead to increased reductions in the utility's future load. Though these effects have been found to be small [52]. Darghouth et al. [52] also addressed a separate feedback mechanism between increasing PV penetration and the timing of time-of-use (TOU) periods; their analysis found that greater PV penetration causes TOU peak periods to shift into the evening hours, which in turn dampens further adoption. Second, we do not represent the feedback effects of changes in retail rate designs or NEM alternatives on overall customer energy consumption (e.g., fixed customer charge may reduce financial incentive to invest in energy efficiency or net billing may encourage DPV system design to maximize exports), all else being equal. Instead, we construct an annual load and PV penetration forecast which is adhered to regardless of these factors. Incorporating such changes into the model will be pursued as a future research effort.

Most Western U.S. utilities, with the exception of some of those in California, currently have distributed generation deployments equivalent to less than $1 \%$ of annual retail sales. It will take them several years to see the kinds of impacts depicted in this analysis, at even the $4 \%$ penetration level, let alone the $8 \%$ level. Accordingly, policymakers and regulators likely have time to study and deliberate changes to NEM, as well as other policy and regulatory actions, before observing material financial impacts. While many of the impacts appear relatively small (on a percentage basis), they demonstrate how underlying ratemaking and regulatory mechanisms can change utility support 
for or customer interest in DERs, and the magnitude of impacts depends critically on utility physical, financial, and operating characteristics.

Author Contributions: P.C. wrote the original draft manuscript, contributed to the project's conceptualization, performed a subset of the formal analysis, and reviewed and edited the final manuscript. A.S. provided supervision of the research activity, led the development of the project's conceptualization, performed a subset of the formal analysis, and reviewed and edited the manuscript. W.G. and J.R. contributed to the project's conceptualization, performed a subset of the formal analysis, and reviewed and edited the manuscript. All authors read and approved the final manuscript.

Funding: This work was supported by the U.S. Department of Energy Solar Energy Technologies Office under Lawrence Berkeley National Laboratory Contract No. DE-AC02-05CH11231. This manuscript has been authored by an author at Lawrence Berkeley National Laboratory under Contract No. DE-AC02-05CH11231 with the U.S. Department of Energy. The U.S. Government retains, and the publisher, by accepting the article for publication, acknowledges, that the U.S. Government retains a non-exclusive, paid-up, irrevocable, worldwide license to publish or reproduce the published form of this manuscript, or allow others to do so, for U.S. Government purposes.

Conflicts of Interest: The authors acknowledge that one of them is also an editor for this journal.

\section{Appendix A FINDER Model Overview}

The FINDER pro forma financial model was developed to quantify the financial impacts on ratepayers, utilities, and shareholders from the deployment of DERs as well as the introduction of alternative regulatory/business models. The basic structure of the model is depicted in Figure A1. What follows is a more detailed description of the different modules within the model.

Utility costs are based on model inputs that characterize current and projected utility costs over the analysis period. The model represents major cost categories of the utility's physical, financial, and operating environment, including fuel and purchased power, operations and maintenance, and capital investments in generation and non-generation assets (i.e., transmission and distribution investments). Some costs are projected using stipulated first year values and compound annual growth rates (CAGRs); other costs are based on schedules of specific investments (e.g., generation expansion plans). The model calculates the utility's ratebase over the analysis period, accounting for increases due to additional capital investments as well as decreases due to depreciation of existing assets. The model also estimates interest payments for debt and returns for equity shareholders based on an authorized amount used to finance capital investments and includes taxes on earnings.

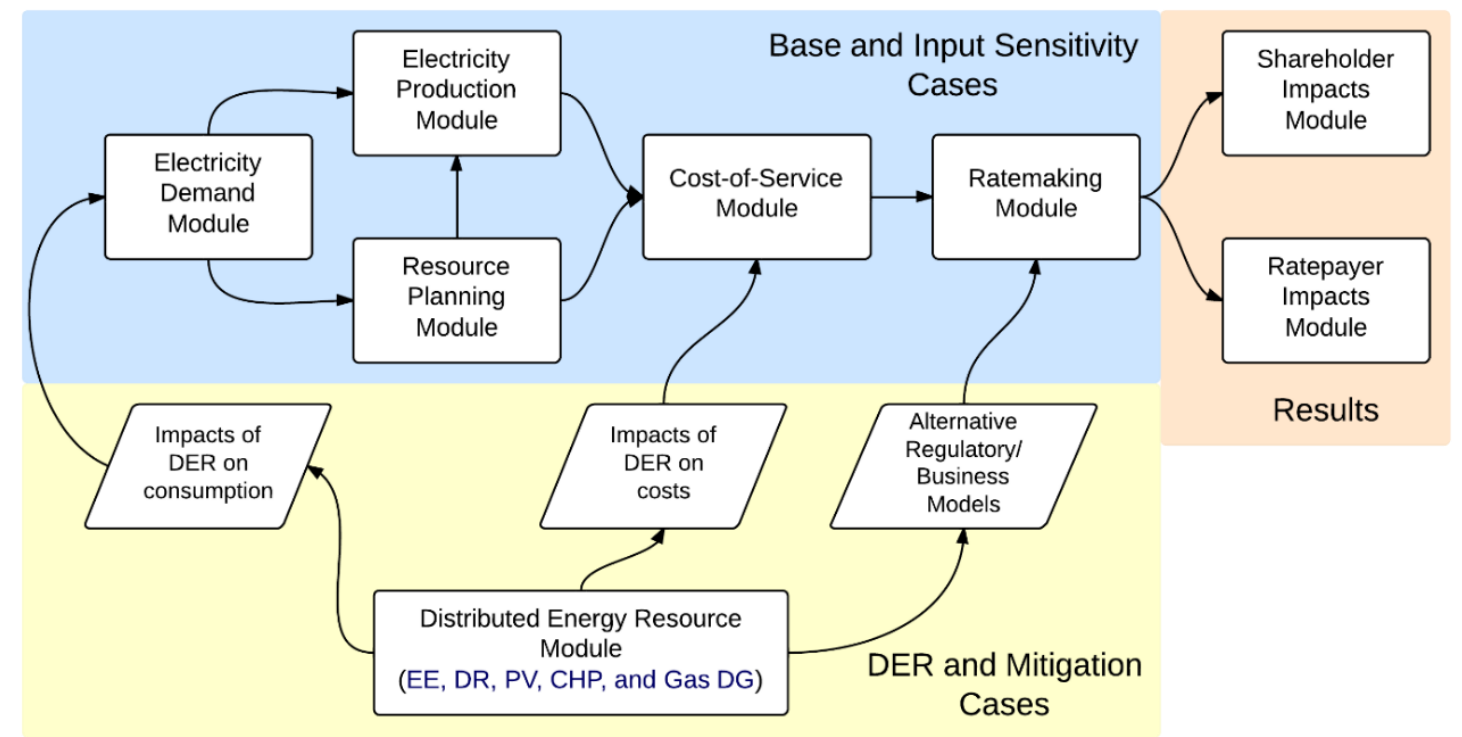

Figure A1. FINDER Model Overview.

The utility's collected revenues are based on retail rates that are set in periodic general rate cases (throughout the analysis period. By default, the model assumes that a GRC occurs at some specified 
frequency (e.g., every three years); the model also allows the utility to file a GRC that may be triggered by a significant capital investment (e.g., new power plant, proposal to install advanced metering infrastructure).

GRCs are used to establish new rates for customers based on the revenue requirement set in a test year, including an authorized ROE for capital investments, the test year billing determinants (i.e., retail sales, peak demand, and number of customers), and assumptions about how the test year revenue requirement is allocated to customer classes and among the billing determinants. The model allows for different types of test years (i.e., historical, current, and future test years). Many states allow the utility to file an adjustment to its historical test-year costs during a GRC (i.e., pro forma adjustment period) to update and correct them to reflect expectations about normal cost levels, however, our model uses unadjusted historic test year values for ratemaking purposes. The particular rate design of the utility consists of a combination of a volumetric energy charge $(\$ / \mathrm{kWh})$, volumetric demand charge $(\$ / \mathrm{kW})$, and fixed customer charge (\$/customer) for a particular customer class. Model inputs specify the relative share of different types of utility costs that are collected from each of these three rate components.

The rates established in a GRC are then applied to the actual billing determinants in future years to calculate utility collected revenue in those years. The model accounts for a period of regulatory lag whereby rates that are established in a GRC do not go into effect until some specified number of years after the GRC. In between general rate cases, certain costs are passed directly to customers through rate-riders (e.g., fuel-adjustment clause or FAC). The model derives an average all-in retail rate metric that reflects the average revenue collected per unit of sales at the utility or customer-class level and accounts for periodic setting of new rates, rate-riders, and delays in implementing new rates.

The financial performance of the utility is measured by achieved after-tax earnings and achieved after-tax ROE. We calculated the prototypical utilities' achieved after-tax ROE in each year as the current year's earnings divided by current year's outstanding equity (i.e., the equity portion of the ratebase). The FINDER Model does not take into account changes in financing costs that may result from underor over-recovery of costs, which may impact ROE. Achieved after-tax ROE may, and often does, differ from the utility's authorized ROE. The authorized ROE is typically established by regulators during a regulatory proceeding and used in a GRC to determine the amount of return that a utility may receive on its capital investments. Actual utility revenues and costs may-and nearly always do-differ from those in the test year, leading to achieved earnings, and hence achieved ROE, that deviates from the authorized level. In a GRC, utility rates are set such that the test-year revenue requirement produces earnings that are sufficient to reach the authorized after-tax ROE based on the test year costs and billing determinants. In general, achieved ROE will be less than authorized ROE if, between rate cases, utility costs grow faster than revenues. Conversely, achieved ROE will generally be greater than authorized ROE if utility costs grow slower than revenues between rate cases.

FINDER calculates the prototypical utilities' achieved after-tax earnings as collected revenues minus costs in each year. Achieved after-tax earnings can be different than the utility's authorized earnings, because the achieved earnings are based on actual profitability in a given year and the authorized earnings are set in the GRC revenue requirement, based on the authorized ROE. Technically, state regulators do not explicitly authorize earnings in a GRC; they authorize a ROE, which when applied to the undepreciated portion of a utility's share of equity financed ratebase produces a level of earnings. For our purposes in this report, we refer to that as authorized earnings.

Alternative regulatory mechanisms and rate structures can also be implemented in FINDER: decoupling mechanisms (i.e., sales based or revenue-per-customer), lost revenue adjustment mechanisms, and shareholder incentive mechanisms. Alternative rate structures (e.g., high fixed customer charge) are represented by changing the way utility revenues are collected among different billing determinants. 


\section{Appendix B Detailed Sensitivity Case Results}

Table A1 shows the sensitivity case results expressed in percentage changes. The change in DPV value is relative to the DPV value in the Base case at the respective DPV deployment level (i.e., $4 \%$ or $8 \%$ ). The change in achieved earnings and average all-in retail rates is relative to a case without DPV.

Table A1. Full sensitivity case results at $4 \%$ and $8 \%$ DPV.

\begin{tabular}{|c|c|c|c|c|}
\hline & Sensitivity Case & $\begin{array}{l}\text { Change in DPV Value } \\
\text { (\% Relative to Base Case) }\end{array}$ & $\begin{array}{l}\text { Change in Earnings } \\
\text { (\% Change Relative to } \\
\text { Respective no DPV) }\end{array}$ & $\begin{array}{l}\text { Change in Average } \\
\text { Retail Rates } \\
\text { (\% Change Relative } \\
\text { to no DPV }\end{array}$ \\
\hline \multirow{4}{*}{$\begin{array}{c}\text { 4\% DPV } \\
\text { Deployment }\end{array}$} & 1.A. (Low Capacity Contribution) & $-4.3 \%$ & $-1.5 \%$ & $1.4 \%$ \\
\hline & 1.B. (High Capacity Contribution) & $6.1 \%$ & $-1.5 \%$ & $0.9 \%$ \\
\hline & 3.A. (Low CapEx Deferral) & $-27.3 \%$ & $-1.6 \%$ & $1.1 \%$ \\
\hline & 3.B. (High CapEx Deferral) & $10.5 \%$ & $-1.5 \%$ & $1.0 \%$ \\
\hline \multirow{4}{*}{$\begin{array}{c}\text { 8\% DPV } \\
\text { Deployment }\end{array}$} & Base & $\mathrm{n} / \mathrm{a}$ & $-3.1 \%$ & $2.4 \%$ \\
\hline & 1.A. (Low Capacity Contribution) & $-4.4 \%$ & $-3.1 \%$ & $3.1 \%$ \\
\hline & 3.A. (Low CapEx Deferral) & $-28.5 \%$ & $-3.2 \%$ & $2.5 \%$ \\
\hline & 3.B. (High CapEx Deferral) & $3.7 \%$ & $-3.0 \%$ & $2.3 \%$ \\
\hline
\end{tabular}

\section{References}

1. SEIA/Wood Mackenzie. Solar Market Insight 2018 Year in Review; Solar Energy Industries Association and Wood Mackenzie Power \& Renewables: Washington, DC, USA, 2016.

2. Barbose, G.; Darghouth, N.; LaCommare, K.H.; Millstein, D.; Rand, J. Tracking the Sun: Installed Price Trends for Distributed Photovoltaic Systems in the United States-2018 ed.; Berkeley Lab: Berkeley, CA, USA, 2018.

3. Sergici, S.; Yang, Y.; Castaner, M.; Faruqui, A. Quantifying net energy metering subsidies. Electr. J. 2019, 32, 106632. [CrossRef]

4. Gautier, A.; Jacqmin, J.; Poudou, J.-C. The prosumers and the grid. J. Regul. Econ. 2018, 53, 100-126. [CrossRef]

5. EEI. A Policy Framework for Designing Distributed Generation Tariffs; Edison Electric Institute: Washington, DC, USA, 2013.

6. The 50 States of Solar: 2017 Policy Review and Q4 2017 Quarterly Report; Clean Energy Technology Center: Raleigh, NC, USA, 2018.

7. Gagnon, P.; Sigrin, B.; Gleason, M. The Impacts of Changes to Nevada's Net Metering Policy on the Financial Performance and Adoption of Distributed Photovoltaics; National Renewable Energy Laboratory: Golden, CO, USA, 2017.

8. Barbose, G.; Miller, J.; Sigrin, B.; Reiter, E.; Cory, K.; McLaren, J.; Seel, J.; Mills, A.D.; Darghouth, N.R.; Satchwell, A. Utility Regulatory and Business Model Reforms for Addressing the Financial Impacts of Distributed Solar on Utilities; Berkeley Lab: Berkeley, CA, USA, 2016.

9. Martín-Martínez, F.; Sánchez-Miralles, A.; Rivier, M.; Calvillo, C.F. Centralized vs distributed generation. A model to assess the relevance of some thermal and electric factors. Application to the Spanish case study. Energy 2017, 134, 850-863. [CrossRef]

10. Averch, H.; Johnson, L. Behavior of the Firm Under Regulatory Constraint. Am. Econ. Assoc. 1962, 51, 1052-1069.

11. Barbose, G. Putting the Potential Rate Impacts of Distributed Solar into Context; Berkeley Lab: Berkeley, CA, USA, 2017.

12. Sandiford, M.; Forcey, T.; Pears, A.; McConnell, D. Five Years of Declining Annual Consumption of Grid-Supplied Electricity in Eastern Australia: Causes and Consequences. Electr. J. 2015, 28, 96-117. [CrossRef] 
13. Schittekatte, T.; Momber, I.; Meeus, L. Future-proof tariff design: Recovering sunk grid costs in a world where consumers are pushing back. Energy Econ. 2018, 70, 484-498. [CrossRef]

14. Borenstein, S. The economics of fixed cost recovery by utilities. Electr. J. 2016, 29, 5-12. [CrossRef]

15. Satchwell, A.J.; Cappers, P.A. Recent developments in competition and innovation for regulated electric utilities. Util. Policy 2018, 55, 110-114. [CrossRef]

16. Gorman, W.; Mills, A.; Wiser, R. Improving estimates of transmission capital costs for utility-scale wind and solar projects to inform renewable energy policy. Energy Policy 2019, 135. [CrossRef]

17. Cohen, M.A.; Kauzmann, P.A.; Callaway, D.S. Effects of distributed PV generation on California's distribution system, part 2: Economic analysis. Solar Energy 2016, 128, 139-152. [CrossRef]

18. Cossent, R.; Gomex, T.; Olmos, L.; Mateo, C.; Frias, P. Assessing the Impact of Distributed Generation on Distribution Network Costs. In Proceedings of the 2009 6th International Conference on the European Energy Market, Leuven, Belgium, 27-29 May 2009.

19. E3. Introduction to the Net Energy Metering Cost Effectiveness Evaluation; CPUC: San Francisco, CA, USA, 2010.

20. Flinn, J.; Webber, C. Residential Zero Net Energy Building Integration Cost Analysis; DNV GL: Oslo, Norway, 2017.

21. Horowitz, K.A.W.; Palmintier, B.; Mather, B.; Denholm, P. Distribution system costs associated with the deployment of photovoltaic systems. Renew. Sustain. Energy Rev. 2018, 90, 420-433. [CrossRef]

22. Mills, A.D.; Barbose, G.; Seel, J.; Dong, C.; Mai, T.; Sigrin, B.; Zuboy, J. Planning for a Distributed Disruption: Innovative Practices for Incorporating Distributed Solar into Utility Planning; LBNL: Berkeley, CA, USA, 2016.

23. Sena, S.; Quiroz, J.; Broderick, R. Analysis of 100 Utility SGIP PV Interconnection Studies. In Proceedings of the 2014 IEEE 40th Photovoltaic Specialist Conference (PVSC), Denver, CO, USA, 8-13 June 2014.

24. Wolak, F. The Evidence from California on the Economic Impact of Inefficient Distribution Network Pricing; NBER: Cambridge, MA, USA, 2018.

25. Passey, R.; Watt, M.; Outhred, H.; Spooner, T.; Snow, M. Study of Grid-connect Photovoltaic Systems-Benefits, Opportunities, Barriers, and Strategies; University of New South Wales: Sydney, Australia, 2007.

26. Stanton, E.; Daniel, J.; Vitolo, T.; Knight, P.; While, D.; Keith, G. Net Metering in Mississippi: Costs, Benefits, and Policy Considerations; For PSC of Mississippi; Synapse: Cambridge, MA, USA, 2014.

27. Xcel. Costs and Benefits of Distributed Solar Generation on the Public Service Compnay of Colorado System; Colorado PUC: Denver, CO, USA, 2013.

28. Hoff, T.E.; Norris, B.; Wayne, G. Potential Economic Benefits of Distributed Photovoltaics to the Nevada Power Company; Clean Power Research: Napa, CA, USA, 2003.

29. Pudjianto, D.; Djapic, P.; Dragovic, J.; Strbac, G. Direct Costs Analysis related to Grid Impacts of Photovoltaics; Imperial College London: London, UK, 2013.

30. TVA. Distributed Generation-Integrate Value: A Methodology to Value DG on the Grid; Tennessee Valley Authority: Knoxville, TN, USA, 2015.

31. Beck, R.W.; Solutions, E.; Company, P.E.; Consulting, S.B. Distributed Renewable Energy Operating Impacts and Valuation Study; For Arizona Public Service; R.W. Beck: Seattle, WA, USA, 2009.

32. Perez, R.; Zweibel, K.; Hoff, T.E. Solar power generation in the US: Too expensive, or a bargain? Energy Policy 2011, 39, 7290-7297. [CrossRef]

33. Poullikkas, A. A comparative assessment of net metering and feed in tariff schemes for residential PV systems. Sustain. Energy Technol. Assess. 2013, 3, 1-8. [CrossRef]

34. Christoforidis, G.; Panapakidis, I.; Papadopoulos, T.; Papagiannis, G.; Koumparou, I.; Hadjipanayi, M.; Georghiou, G. A Model for the Assessment of Different Net-Metering Policies. Energies 2016, 9, 262. [CrossRef]

35. Eid, C.; Reneses Guillén, J.; Frías Marín, P.; Hakvoort, R. The economic effect of electricity net-metering with solar PV: Consequences for network cost recovery, cross subsidies and policy objectives. Energy Policy 2014, 75, 244-254. [CrossRef]

36. Picciariello, A.; Vergara, C.; Reneses, J.; Frías, P.; Söder, L. Electricity distribution tariffs and distributed generation: Quantifying cross-subsidies from consumers to prosumers. Util. Policy 2015, 37, 23-33. [CrossRef]

37. Johnson, E.; Beppler, R.; Blackburn, C.; Staver, B.; Brown, M.; Matisoff, D. Peak shifting and cross-class subsidization: The impacts of solar PV on changes in electricity costs. Energy Policy 2017, 106, 436-444. [CrossRef]

38. Satchwell, A.; Cappers, P.; Goldman, C. Customer bill impacts of energy efficiency and net-metered photovoltaic system investments. Util. Policy 2018, 50, 144-152. [CrossRef] 
39. Satchwell, A.; Mills, A.; Barbose, G. Quantifying the financial impacts of net-metered PV on utilities and ratepayers. Energy Policy 2015, 80, 133-144. [CrossRef]

40. WECC. TEPPC Study Report: 2026 PC1 Common Case; Western Electricity Coordinating Council: Salt Lake City, UT, USA, 2017.

41. Darghouth, N.; Barbose, G.; Wiser, R. The impact of rate design and net metering on bill savings from distributed PV for residential customers in California. Energy Policy 2011, 39, 5243-5253. [CrossRef]

42. Darghouth, N.; Barbose, G.; Wiser, R. Electricity bill Savings from Residential Photovoltaic Systems: Sensitivities to Changes in Future Electricity Market Conditions; Berkeley Lab: Berkeley, CA, USA, 2013.

43. Darghouth, N.; Barbose, G.L.; Mills, A.D.; Wiser, R.H.; Gagnon, P.; Bird, L. Exploring Demand Charge Savings from Residential Solar; Berkeley Lab: Berkeley, CA, USA, 2017.

44. EIA. Capital Cost Estimates for Utility Scale Electricity Generating Plants; Energy Information Administration: Washington, DC, USA, 2016.

45. National Renewable Energy Laboratory Annual Technology Baseline. Data and Documentation. Available online: https://atb.nrel.gov/electricity/2018/index.html (accessed on 18 June 2018).

46. Satchwell, A.; Mills, A.; Barbose, G.; Wiser, R.; Cappers, P.; Darghouth, N. Financial Impacts of Net-Metered PV on Utility and Ratepayers: A Scoping Study of Two Prototypical US Utilities; Berkeley Lab: Berkeley, CA, USA, 2014.

47. National Renewable Energy Laboratory Distributed Generation Energy Technology Operations and Maintenance Costs. Data and Documentation. Available online: https:/www.nrel.gov/analysis/techcost-om-dg.html (accessed on 8 August 2018).

48. CPUC. Residential Zero Net Energy Building Integration Cost Analysis; California Public Utilities Commission: San Francisco, CA, USA, 2017.

49. Blair, N.; DiOrio, N.; Freeman, J.; Gilman, P.; Janzou, S.; Neises, T.; Wagner, M. System Advisor Model (SAM) General Description (Version 2017.9.5); National Renewable Energy Laboratory: Golden, CO, USA, 2018.

50. Rhodes, J.D.; Upshaw, C.R.; Cole, W.J.; Holcomb, C.L.; Webber, M.E. A Multi-objective Assessment of the Effect of Solar PV Array Orientation and Tilt on Energy Production and System Economics. Sol. Energy 2014, 108, 28-40. [CrossRef]

51. Satchwell, A.; Cappers, P.; Schwartz, L.; Fadronc, E.M. A Framework for Organizing Current and Future Electric Utility Regulatory and Business Models; Berkeley Lab: Berkeley, CA, USA, 2015.

52. Darghouth, N.; Wiser, R.H.; Barbose, G.L.; Mills, A. Net Metering and Market Feedback Loops: Exploring the Impact of Retail Rate Design on Distributed PV Deployment. Appl. Energy 2016, 162, 713-722. [CrossRef] 